\title{
Mobile Devices and Applications Use for Students of Technological Education
}

\author{
Halina Rarot ${ }^{1 *}$, Olexandr Omelchuk ${ }^{2}$, Vitaliy Tsisaruk ${ }^{2}$ \\ 1 Fundamentals of Technology Faculty, Lublin University of Technology, Nadbystrzycka 38, 20-618 Lublin, \\ Poland \\ 2 Department of Theory and Methods of Work Raining and Technologies of Taras Shevchenko Kremenets \\ Regional Humanitarian Pedagogical Academy, Kremenets, Ukraine \\ * Corresponding author's e-mail: rarot@nowanet.pl
}

\begin{abstract}
The key points of mobile devices use in the education system were determined. The examples of tasks that can be solved using these tools were given. The main possibilities of using mobile gadgets in educational activities during visualization of demonstration material, questionnaires, testing, and also during distance learning were considered. The systematic mobile devices use was indicated in order to improve the efficiency of the educational process.
\end{abstract}

Keywords: mobile learning, mobile devices, mobile technologies, online resource, gadget, smart phone.

\section{INTRODUCTION}

Today, almost all students have a mobile device. Moreover, mobile devices are used by students not only for communication, entertainment, or for obtaining diverse information, but also for solving various educational tasks. Mobile devices can also provide the student with the ability to search information, especially when no personal computer is available nearby. Submitting the information in a more convenient form is exactly what the student needs at the right moment.

The emergence of specialized programs and mobile applications for training has recently been seen as an opportunity to use them in the educational process. The analysis of world trends demonstrates the vital acuity of employing mobile applications in education for solving various pedagogical tasks, organization of remote access to general network as well as specialized resources and educational institutions services.

The timeliness of mobile technologies use in the educational environment is conditioned by the following prerequisites: a high level and dynamics of the distribution of mobile devices, a steady interest in their application, the ability to turn educational and methodogical complexes into media content and the related content in the infrastructure of educational and research space.

The use of mobile devices in the educational process provides the opportunity to create personalized professional and person-oriented learning space. However, despite the relatively high level of opportunities for organizing their own educational space, students are not fully using the functions of mobile devices and available software applications for this purpose. This is confirmed by one of the main postulates of pedagogical science that the role of a teacher in the organization of all types of training is very significant and how he understands the didactic functions of mobile means of learning depends on the quality of the educational process in the modern information society [Malezhik, 2014].

The problem of using new mobile devices and applications in learning is not new, but it does not cease to be relevant, as can be seen from the numerous works published in recent years in methodological literature. Globally, this problem is dealt with in works: (Roy, 2017; Diliberto-Ma- 
caluso and Hughes, 2016, Gangaiamaran and Pasupathi, 2017) - theoretical and historical aspects of mobile learning; (Malezhik, 2014) - use of mobile devices in educational processes of high and secondary schools.

Since the analysis of the work showed that modern mobile applications are necessary educational tools, and mobile devices become more portable, accessible and easy to use, it leads to their spread and application among the student youth. However, this process is mostly spontaneous and unsystematic.

The application of educational technology and mobile-based applications today requires a detailed analysis and systematization in the study of various disciplines by future technology teachers.

Thus, the purpose of the article was to describe the main opportunities of using mobile applications for teaching various disciplines by students of engineering and pedagogical education.

\section{MOBILE DEVICES AND APPLICATIONS}

Today, during the reform of the "New Ukrainian School", teachers have the opportunity to apply new active learning technologies. In particular, it is a mobile learning technology based on the intensive use of modern mobile devices and applications.

In the work [Malezhik, 2014], the authors note that such didactic properties of mobile devices, such as mobility, interactive, multimedia, communicative, and productivity, can be used as a pedagogical toolkit. These properties of mobile devices provide an opportunity to organize a wide range of different types of educational activities, including: informational and educational, educational games, experimental research, independent activities for the processing of information, including audiovisual. The authors point out that the methodological aspects of learning using mobile devices include: significant information capacity of educational material, a variety of information sources, which leads to an increase in the forms of organization of educational activities; creating an interactive communicative situation through the use of various functions of mobile devices and applications in the main types of learning activities; independent work organization of each student; mastering different models and structures of phenomena and processes; increase of cognitive activity of the student, and also strengthening the motivation of studying at the expense of the correspondence of educational tools to the ageold peculiarities of perception of their life in a digital society [Malezhik, 2014].

As for the "mobile application" - this is a special program that is installed by the user on a mobile device, usually through markets (portals, shops, marketplaces). The most popular ones are AppStore, and GooglePlay, where mobile applications have billions of different purposes for every taste: various games and entertainment, media, magazines, books, social networks, giant trading platforms, hotel reservations, restaurant and cafe delivery orders, mobile versions of dating services, weather applications, exchange rates, fuel prices, health applications that track patients' health, access to bank accounts, and so on.

In general, the applications pursue at least two explicit goals: provide entertainment and make life easier -in other words, there are both useless and useful mobile applications [https://www. quality-assurance-group.com/mobilnyj-dodatokvnosymo-rozuminnya-u-znachennya-terminu/].

Let us consider the most useful mobile applications for obtaining and assimilating knowledge by future technology teachers in Ukraine during the study of various disciplines.

While studying the «Theory and methodology of vocational guidance work» discipline, students of technological education are introduced to a variety of ways to choose a future profession. In this case, the "Coursera» mobile application can be used. It provides the access to a thousand courses of different specializations. Knowing this application, students of technological education will be able to use it during educational activities related to vocational guidance work at school. The utility is free and available to both Android and iOS users.

While studying the «Electrical Engineering» discipline it is expedient to use the "AutoCAD Electrical» mobile application - an automated design system designed for the development of power supply systems, transport, electrical control systems, relay protection, etc. Thus, with AutoCAD Electrical, students can create «Electrical Circuits» easily and without errors. AutoCAD Electrical is one of the most popular applications for designing automation systems. 
Prometheus is a free mobile application and an Innovative Design Course, which helps future technology teachers to design products while studying the "Design Principles" discipline [https://courses.prometheus.org.ua/courses/ course1:Prometheus+DTI101+2017_T3/about].

AutoCAD mobile DWG viewer is an application with easy-to-use drawing and drawing tools that enable to view, create, edit and share drawings on mobile devices - anytime and anywhere. This application can be used in studying the discipline «Descriptive geometry and drawing.»

Student versions of AutoCAD, intended exclusively for use by students and teachers for educational purposes, are available for free download from the Autodesk Educational Community. Functionally, the student version of AutoCAD is no different from the full one, with one exception: the DWG files created or edited in it have a special tag (so-called educational flag) that will be placed in all types when printing a file (regardless of which version - student or professional - print is done). The objects created in student versions cannot be used for commercial use. These objects «infect» the DWG files created in a commercial version, if imported [https://play.google.com/ store/apps/category/EDUCATION/collection/ topselling_free? $\mathrm{hl}=\mathrm{ru}-]$.

\section{THE APPROACH TO EDUCATIONAL PROCESS}

In the field of higher technological education, one of the most important tasks of controlling the effectiveness of training is the objective assessment of the level of knowledge, skills, and habits of students. One of these methods is testing, without which no teacher can do today.

The new direction of software testing is the application of mobile applications, which can include the following:

- Kahoot! - this service is not only for creating a variety of test forms, but for conducting online quizzes with the help of a special client installed on the student's smartphone (Android, iOS, Windows Phone). It allows the teacher to diagnose the responses of students, and to correct the answers of those who are being taught. Free, requires registration.

- Quizlet is a service for creating tests in which the correct answer from the proposed options is selected. The service is free and multilin- gual, its main feature is that it works on Android and iOS smartphones. Registration is required.

- Plickers - a service in the form of a mobile application that enables to arrange polls on students' smartphones and analyze the teacher statistics for all students. The Android and iOS app downloads for free.

- Easy Test Maker is a service in the form of a mobile application for creating tests in which to choose the true and false statements. In order to test in a more traditional format, they can be formatted in .pdf or .doc format for printing. It is free for the review period [http: //www.dut.edu.ua/ua/news-1-626-5118-nazametku-prepodavately-platformy-dlya-sozdaniya- testov].

The most effective use of mobile devices can be found in the organization of such types of educational process as:

- Educational and methodogical material notification, executed in electronic form, for preliminary examination and for independent work;

- Formation of information databases for works, articles and abstracts;

- Work with curricula or resources;

- Educational work planning, electronic diary, schedule of occupations, telephones and addresses;

- Use of databases (directories, translators, educational programs);

- Work in information networks Internet.

Such an approach to conducting an educational process enables the teacher and student to save time in solving the organizational issues.

The Android-based mobile devices provide a wealth of opportunities for student learning and have great prospects for use in the educational process. The usage of mobile applications as modern means of technological education contributes to the formation of the technological culture of the individual, the activation of students' educational interest, and brings educational activities in the university to real, everyday life.

Therefore, the training of future technology teachers cannot be effectively implemented without the use of modern mobile devices and applications, as in today's information society; there was a need for educators with a high level of mobile technology. 


\section{CONCLUSIONS}

Further prospects of technological education development are unthinkable without the emergence and use of a number of mobile devices and applications that will make a significant contribution to the process of obtaining and assimilating knowledge by future technology teachers.

\section{REFERENCES}

1. Design thinking for innovation [Electronic resource] - Access mode: https://courses.prometheus.org.ua/ courses/course 1:Prometheus+DTI101+2017_T3/ about. - Title from the screen.

2. Diliberto-Macaluso Kristen and Hughes Alan 2016. The Use of Mobile Apps to Enhance Student Learning in Introduction to Psychology. Teaching of Psychology, 43, 48-52. DOI: 10.1177/ 0098628315620880.

3. Education - Top Free [Electronic Resource] - Access Mode: https: //play.google.com/store/apps/ category/EDUCATION/collection/topselling_ free $\mathrm{hl}=$ ru- Title from the screen.
4. For Teachers' Note: Testing Platforms [Electronic Resource] - Access Mode: http: //www.dut.edu.ua/ ua/news-1-626-5118-na-zametku-prepodavatelyplatformy-dlya-sozdaniya- testov - Title from the screen.

5. Malezhik P. 2014. The use of mobile device devices in the learning process. In: P. Malezhik. M. Malezhik (Eds.) Psychological-pedagogical problems of rural school, Iss. 48, 102-107.

6. Mobile application - we make an understanding of the meaning of the term [Electronic resource] - Access mode: https:/www.quality-assurancegroup.com/mobilnyj-dodatok-vnosymorozuminnya-u-znachennya-terminu/ Title from the screen.

7. Roy S. 2017. 5 Benefits of Using Mobile Apps In Education [Accessibility] - Access Mode: https: // elearningindustry.com/mobile-apps-in-education5-benefits.

8. Ramya Gangaiamaran and Madhumathi Pasupathi, 2017. This Is How Mobile Apps In Classrooms Can Help Students Immensely [Electronic resource] Access Mode: http: //www.businessofapps.com/ news/this-is-how-mobile-apps-in-classrooms-canhelp -students-immensely / - Title from the screen. 